\title{
Surgical outcome of posterior decompression, posterolateral fusion and stabilization by pedicle screw and rod in thoracolumbar tuberculosis
}

\author{
Md. Anowarul Islam, Md. Naimur Rahman and Md. Fahad Goni
}

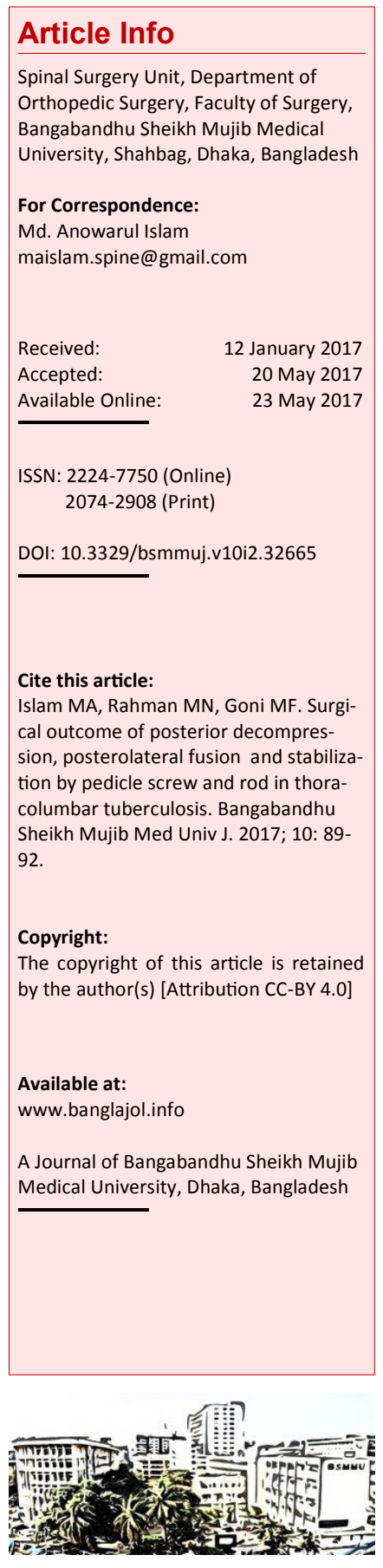

\begin{abstract}
Spinal tuberculosis causes severe complications like neurological and spinal deformity which may lead to respiratory distress, costo-pelvic impingement, paraplegia and consequent reduction in the quality and longevity of life. The aim of the present treatment is to avoid the consequence of neural complications and gain near-normal spine. Mechanical factor causes pathological fracture or dislocation of an affected vertebral body. Surgical decompression ensues further instability. Reconstruction of spinal column by pedicle screw and rod provide stability and prevents secondary neural damage and deformity thereby helps in early mobilization. Prospective study was done to evaluate the results in 20 cases of spinal tuberculosis in thoracolumbar region associated with neurological deficit. We operated our cases (12 males and 8 females) by posterolateral decompression, fusion and stabilization by pedicle screw and rod along with antitubercular drug treatment. All patients were with neurological deficit, single level involvement and 10 to 30 degree of mild kyphosis. After surgery, kyphosis improved from $20.7 \pm 5.5$ degrees to $12.5 \pm 3.9$ degree. Bony fusion was in $65.0 \%$ cases. Neurological improvement and pain subsided in all the patients.
\end{abstract}

\section{Introduction}

Approximately one-third of the world's population is infected with Mycobacterium tuberculosis. The disease is thought to cause at least 3 million deaths each year.1 About $16 \%$ of newly reported cases of tuberculosis involve extrapulmonary sites.? Skeleton is one of the important sites for extrapulmonary tuberculosis. Spinal involvement occurs in less than $1 \%$ of patients with tuberculosis. .4 Spinal tuberculosis (Pott's disease) is the most common as well as one of the most dangerous forms of skeletal tuberculosis and accounts for $50 \%$ of all cases of skeletal tuberculosis. Although the thoracolumbar junction seems to be the most common site of the spinal column involvement in spinal tuberculosis, any part of the spine can be affected. $\frac{5}{-}$

Approach for surgical treatment of the thoracolumbar tuberculosis is always controversial. The goals of surgery in Pott's spine are adequate decompression, adequate debridement, maintenance and reinforcement of stability and correction and prevention of deformity. Traditionally, the anterior approach has been preferred throughout the spine to achieve these goals because the pathology of tuberculosis mainly affects the vertebral bodies and disc spaces, and the anterior approach allows direct access to the infected focus and is convenient for debriding infection and reconstructing the defect.6-8 In the thoracic and lumbar region, anterior instrumentation to provide bone stability may be tenuous because the concomitant osteoporosis associated with infection renders the vertebrae structurally weak and may prevent adequate fixation. 9

This prospective study was carried out to evaluate the efficacy of posterior decompression and fixation in thoracic and thoracolumbar tuberculosis with definite surgical indication in the skeletally mature patients.

\section{Materials and Methods}

Twenty patients (12 males; 8 females) with age between 13-66 years (mean, 39.7 years) were taken from July 2011 to June 2015. In all the cases, 2 adjacent vertebrae was involved and neurological deficit was present and confirmed by FNAC for diagnosis of tuberculosis. Involvements of more than 2 segments were excluded from the study.

Hematological investigations (complete blood count with ESR, random blood sugar, serum 
creatinine, liver function test), chest X-Ray and MRI of the spine were done before starting antitubercular drugs 4 FDC for 3 months and 2 FDC for 18 months. The patients were selected who had Frankel grade A/B paraplegia and Frankel grade $\mathrm{C} / \mathrm{D}$ paraplegia who were not responded to antitubercular drugs within 6 weeks and/or patients with intractable pain with VAS score more than five.

\section{Methods}

With all aseptic precaution under general anesthesia, we positioned the patient in prone keeping 1 pillows under the chest and pelvis thereby keeping the abdomen free from pressure. Posterior midline incision was given. Paravertebral muscle was retracted and pedicle screw was inserted in the unaffected vertebra which was one level above and below the diseased site. The diseased vertebrae were avoided because of loosening of

\begin{tabular}{|lccc|}
\hline \multicolumn{4}{|c|}{ Table I } \\
\hline \multicolumn{4}{|c|}{ Pre- and post-operative data of patients } \\
\hline Variable & Pre-operative & Post-operative & p value \\
\hline VAS & $5.5 \pm 0.8$ & $0.3 \pm 0.6$ & $<0.001$ \\
Kyphotic angle (degree) & $20.7 \pm 5.5$ & $12.5 \pm 3.9$ & $<0.001$ \\
Correction of kyphotic angle & & $8.2 \pm 3.1$ & \\
(degree) & & & \\
Fusion (n) & & 13 & \\
ESR (mm in 1st hour) & $63.5 \pm 10.7$ & $21.3 \pm 2.9$ & $<0.001$ \\
Frankel grade & & & \\
$\quad$ A & 7 & 0 & \\
B & 8 & 0 & \\
C & 3 & 11 & \\
\multicolumn{1}{|c|}{ D } & 2 & 9 & \\
\hline E & 0 & 0 & \\
\hline
\end{tabular}

Data are mean \pm SD

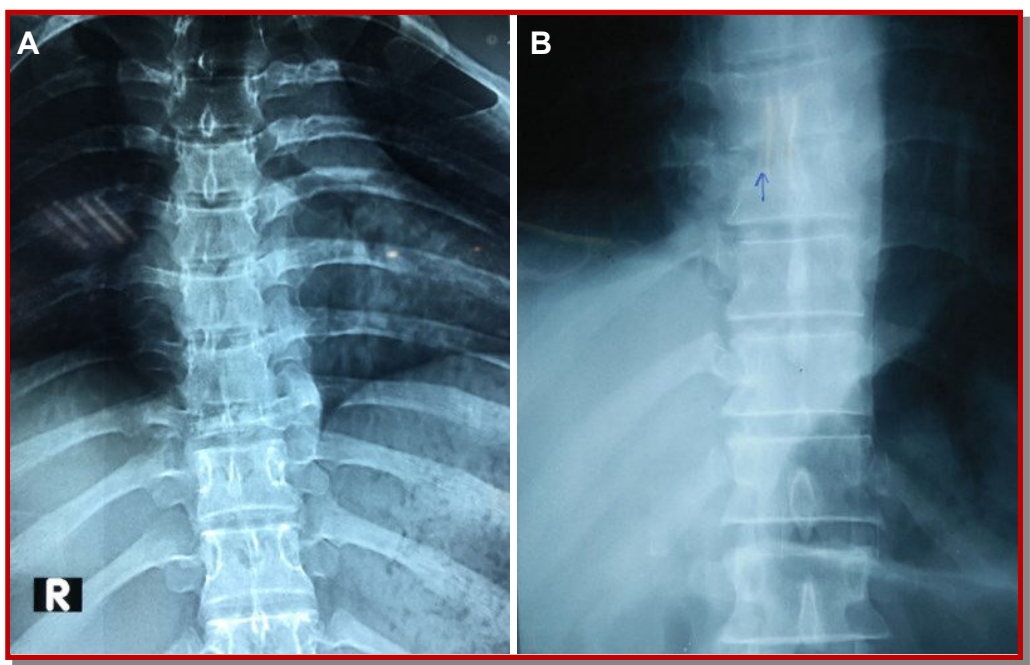

Figure 1: Involvement of D5 vertebral body (A) and dorsal disc space (B) are shown in X-Ray plates screw with subsequent abscess formation. Decompression was performed at the diseased level after pedicle screw insertion. At first, the inferior part of the adjacent superior vertebrae were excised. Then the diseased vertebra along with upper facet and pedicle were removed. Part of the lamina was excised so that the exiting nerve roots become visible. After retracting the exiting nerve root, the disc along with granulation tissues was removed and sequestrated bone by disc rongeur. Histopathological examination was done. Finally after proper contouring, connecting rods were fixed with pedicle screw on each side.

\section{Post-operative treatment}

After 3 weeks with the support of tailor brace (thoracolumbosacral otrhosis), patient was allowed to sit. The brace was discarded after 6-8 months after seeing the radiological fusion or patient become pain free. The exercise for building-up muscle power of lower limbs was advised and started gradual ambulation.

\section{Follow-up}

Stitch was removed at $14^{\text {th }}$ post-operative day. Patients were advised to come at 3 months interval for follow-up.

X-Ray was done at each follow-up to see sclerosis in contiguous vertebral bodies, resolution of abscess shadows, implants position, angle of kyphosis and fusion. After completion of antitubercular drugs, lateral view of X-Ray in flexion extension of spine was done to see any evidence of instability.

ESR was done regularly to see the disease status. Liver function test was done at regular interval to see the toxic effect of antitubercular chemotherapy. Measurement of kyphotic angle was done from lateral view of X-Ray of spine by the method described by Knostam and Blesovsky. 10 Paired ' $t$ ' test was done to compare pre-operative and postoperative kyphotic angle.

\section{Results}

Patients mean age was 39.7 years (13-66 years). No patients were suffering from major medical illness. Pain was relieved significantly in all patients with improvement of VAS from $5.5 \pm 0.8$ pre-operative to $0.3 \pm 0.6$ at 4 months (Table I). ESR declines in all patients from between 48 and $85 \mathrm{~mm}$ in $1^{\text {st }}$ hour pre -operatively and came down to $<25$ at 1 year followup. All patients were recovered neurologically. Eleven patients $(55.0 \%)$ recovered neurologically to Frankel grade E and $9(45.0 \%)$ patients were recovered to Frankel grade D. Thirteen $(65.0 \%)$ patients showed radiological fusion, and $7(35.0 \%)$ patients did not achieve fusion. However, the nonunion patients remained asymptomatic performing 

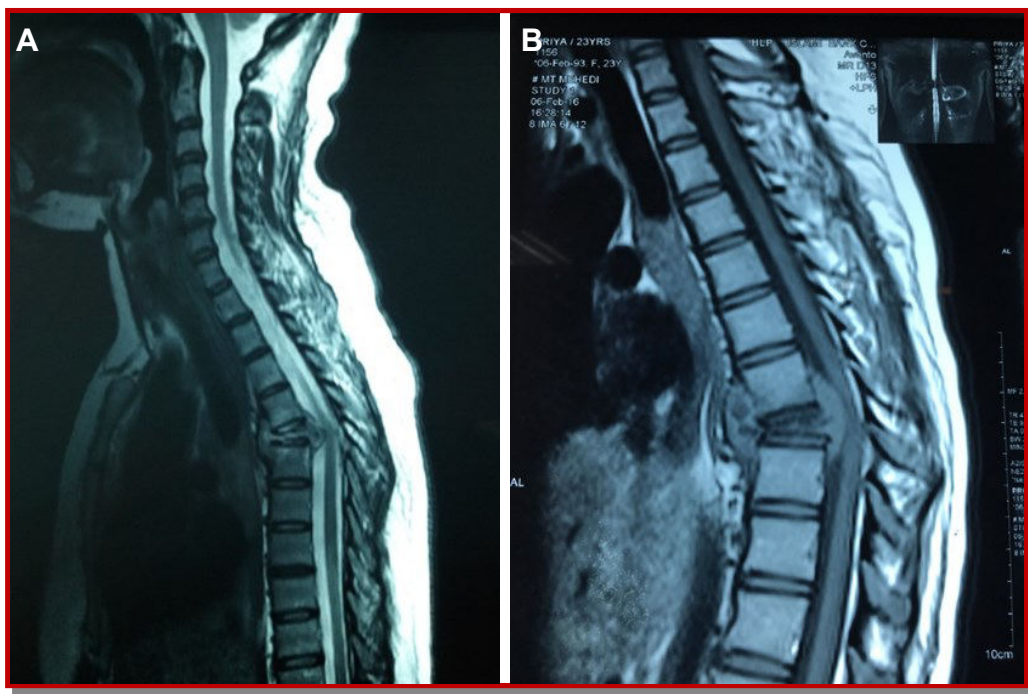

Figure 2: Involvement of D5 vertebral body (A) and D8 vertebra (B) are shown in MRI films

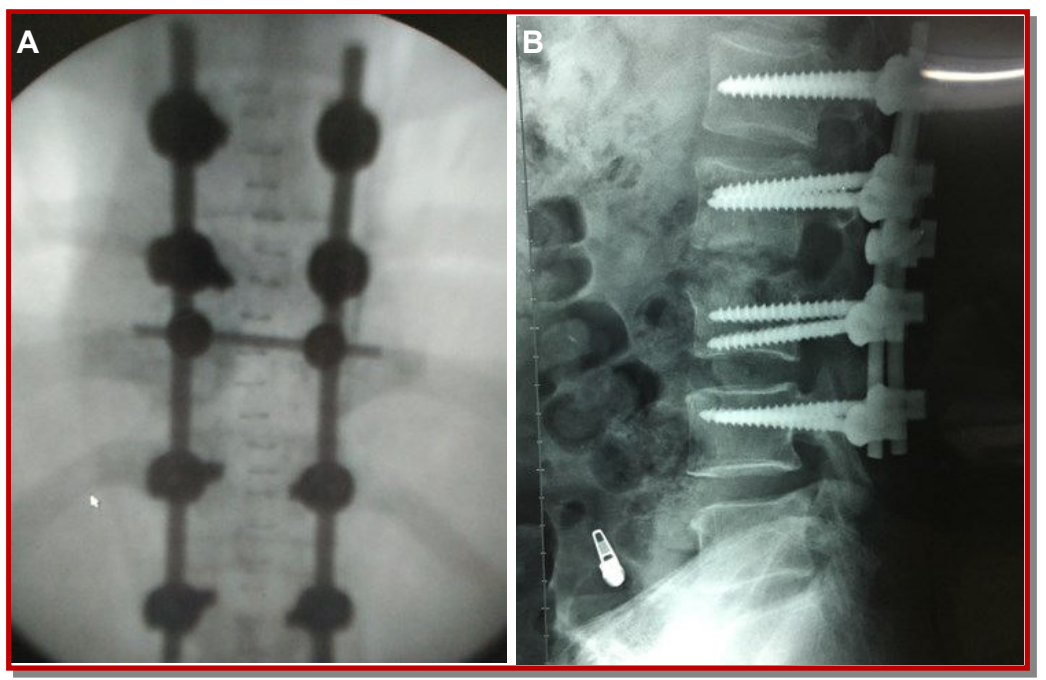

Figure 3: Peroperative (A) and post-operative (B) X-Ray plates of fixation

their normal daily activities as normal with no radiological feature of instability. In the preoperative period mean kyphotic angle was $20.7 \pm 5.5$ degrees and post-operatively it was corrected to $12.5 \pm 3.9$ degrees and average correction of $8.2 \pm 3.1$ degrees (Figure 1-3). Bed sore was the most common complication which occurred in four patients, two deep and two superficial. Four patients were suffering from urinary infection. But there was no incidence of wound infection or dehiscence or implant failure.

\section{Discussion}

In this study, all cases were in early active stage with vertebral body destruction less than $50 \%$ along with neurological deficits. In this study, pain was relieved significantly in all patients with improvement of VAS from $5.5 \pm 0.8$ pre-operative to $0.3 \pm 0.6$ at 4 months. All patients had significant post-operative improvement in VAS scores. $.11,12$ In this study, kyphotic angle was reduced from $20.7 \pm$ 5.5 degrees to $12.5 \pm 3.9$ degrees and average correction was $8.2 \pm 3.1$ degrees. The thoracic kyphotic angle was significantly decreased to $11.6^{\circ}-$ $20.2^{\circ}$ after operation and the angle was $12.3^{\circ}-21.6^{\circ}$ at final follow-up. $\underline{.2}$ Similar to Lee et al.11 study, Frankel grade was improved in all cases in this study. In the present series, fusion was seen in 13 $(65.0 \%)$ patients within $12-24$ months follow-up. All patients have got spontaneous bony fusion within 6 -9 months after surgery. 12

\section{Conclusion}

Though anterior spine surgery is a good option, the present method is superior as because of less surgical risk in early stage.

\section{References}

1. Dye C, Scheele S, Dolin P, Pathania V, Raviglione MC. Consensus statement. Global burden of tuberculosis: Estimated incidence, prevalence, and mortality by country. WHO Global Surveillance and Monitoring Project. JAMA. 1999; 282: 677-86.

2. Centers for disease control and prevention: Reported tuberculosis in the United States, 1997. Atlanta, Centers for disease control and prevention, 1998.

3. Turgut M. Spinal tuberculosis (Pott's disease): Its clinical presentation, surgical management, and out -come. A survey study on 694 patients. Neurosurg Rev. 2001; 24: 8-13.

4. Rezai AR, Lee M, Cooper PR, Errico TJ, Koslow M. Modern management of spinal tuberculosis. Neurosurgery 1995; 36: 87-97.

5. Moorthy S, Prabhu NK. Spectrum of MR imaging findings in spinal tuberculosis. Am J Roentgenol. 2002; 179: 979-83.

6. Garg B, Kandwal P, Nagaraja UB, Goswami A, Jayaswal A. Anterior versus posterior procedure for surgical treatment of thoracolumbar tuberculosis: A retrospective analysis. Indian J Orthop. 2012; 46: 165.

7. Benli T, Kaya A, Acaroglu E. Anterior instrumentation in tuberculous spondylitis: Is it effective and safe? Clin Orthop Relat Res. 2007; 460: 108-16.

8. Jain AK, Dhammi IK, Prashad B, Sinha S, Mishra P. Simultaneous anterior decompression and posterior instrumentation of the tuberculous spine using an anterolateral extrapleural approach. J Bone Joint Surg Br. 2008; 90: 1477-81.

9. Hee HT, Majd ME, Holt RT, Pienkowski D. Better 
treatment of vertebral osteomyelitis using posterior stabilization and titanium mesh cages. J Spinal Disord Tech. 2002; 15: 149-56.

10. Konstam PG, Blesovsky A. The ambulant treatment of spinal tuberculosis. Br J Surg. 1962; 50: 26-38.

11. Lee SH, Sung JK, Park MK. Single-stage transpedicular decompression and posterior instrumen- tation in treatment of thoracic and thoracolumbar spinal tuberculosis: A retrospective case series. J Spinal Disord Tech. 2006; 19: 595-602.

12. Wu P, Wang XY, Li XG, Shen XJ, Pang XY, Luo CK, $\mathrm{Xu} Z \mathrm{ZQ}$, Zeng H, Zhang PH, Peng W. One-stage posterior procedure in treating active thoracic spinal tuberculosis: A retrospective study. Eur J Trauma Emerg S. 2015; 41: 189-97. 